\title{
Primary angiosarcoma of the ovary with prominent fibrosis of the ovarian stroma. Case report of an 81-year old patient
}

\author{
Hans Bösmüller ${ }^{1 *}$, Christine Gruber ${ }^{1}$, Sophie Haitchi-Petnehazy ${ }^{1}$, Dietmar Wagner ${ }^{2}$, Gerald Webersinke ${ }^{3}$ and \\ Steffen Hauptmann ${ }^{4}$
}

\begin{abstract}
Primary angiosarcoma of the ovary (AS) is a rare entity with only 31 reported cases. The majority are pure angiosarcomas, the remainder are associated either with teratomas or conventional epithelial tumors. More than $50 \%$ of ovarian AS are disseminated at the time of diagnosis, the minority is detected in stage I. The prognosis of ovarian angiosarcoma in general is poor. Most reports refer to younger individuals, aged from 7 to 46 years, and only 2 case reports could be found for patients older than 64 years. Here we present a very unusual case of angiosarcoma in a 81-year-old patient.
\end{abstract}

Virtual Slides: The virtual slide(s) for this article can be found here: http://www.diagnosticpathology.diagnomx.eu/ vs/35073434354334581.

\section{Background}

Primary angiosarcomas (AS) of the ovary are rare malignancies. Approximately $25 \%$ of them are associated with other neoplasms, e.g. mature cystic teratoma, [1-3], mucinous cystadenoma, serous and mucinous carcinoma, [4-6], or fibroma [7]. Metastases to the ovary from soft tissue AS rarely occur $[8,9] .60 \%$ of all reported AS were detected in stage III and IV [1-4,6,10-18]. Surgical debulking and chemotherapy provided only short disease-free intervals, and most patients died from lung metastasis within 9 months. Twelve reports with stage I disease indicated better outcome, with only two patients dying within one year $[3,5,7,17,19-23]$. Ovarian AS usually affects premenopausal women or even children [24], with only two reports in postmenopausal individuals $[7,18]$ (Table 1). Here we describe the oldest patient reported with ovarian AS so far.

\section{Case Presentation}

\section{Patient}

The 81-year-old patient was admitted to the hospital with abdominal pain and distension. Ultra-sonography

\footnotetext{
* Correspondence: hans-christian.boesmueller@bhs.at

'Department of Pathology, Krankenhaus Barmherzige Schwestern Linz, Austria

Full list of author information is available at the end of the article
}

and computed tomography revealed a huge cystic mass of the right ovary. There were no signs of distant tumor deposits. The patient underwent hysterectomy and adnexectomy on the right, the left adnexa had been taken out decades ago. Further exploration of the abdomen and all other clinical investigations were without pathological findings, six weeks after laparatomy the patient underwent chemotherapy with 4 cycles of doxyrubicin, and after an follow up of 5 months she is still alive, and there are no signs of recurrence.

Macroscopically the tumor had a weight of 2122 grams and measured 30:18:12 cm. The peritoneal surface was inconspicuous. The cut surface showed a big central cyst with a diameter of $14 \mathrm{~cm}$, containing hemorrhagic debris and some luminal projections. The cyst wall and its immediate surrounding consisted of yellowish fibrous tissue with some myxoid glistening changes and hemorrhagic areas, but no significant necrosis (Figure 1). Microscopically, the cyst wall was composed of fascicularly arranged, densely packed atypical spindle cells with pleomorphic nuclei and sparse cytoplasm. Up to 4 mitoses per high power field were counted. Focally, these spindle cells formed Kaposi-like angiomatous spaces containing erythrocytes. Other tumor components had a more epitheloid character. At
C Biomed Central

(c) 2011 Bösmüller et al; licensee BioMed Central Ltd. This is an Open Access article distributed under the terms of the Creative Commons Attribution License (http://creativecommons.org/licenses/by/2.0), which permits unrestricted use, distribution, and reproduction in any medium, provided the original work is properly cited. 
Table 1 Survey of all reported cases of ovarian angiosarcoma including histologic type, stage, author, year of publication and citation number

\begin{tabular}{|c|c|c|c|c|c|c|}
\hline NR & AGE & HISTOLOGY & STAGE & AUTHOR & YEAR & CITATION \\
\hline 1 & 7 & AS & $?$ & Evtushenko NT & 1958 & 24 \\
\hline 2 & 19 & AS & IV & Cunningham MJ & 1994 & 10 \\
\hline 3 & 19 & AS & III & Davidson B & 2005 & 16 \\
\hline 4 & 20 & AS & I & Nielsen GP & 1997 & 3 \\
\hline 5 & 21 & AS & IV & Bouchi J & 1993 & 12 \\
\hline 6 & 25 & AS & III & Nucci MR & 1998 & 17 \\
\hline 7 & 25 & AS & III & Lifschitz-Mercer B & 1998 & 22 \\
\hline 8 & $20-32 *$ & AS & I & Nielsen GP & 1997 & 3 \\
\hline 9 & $20-32 *$ & AS & 1 & Nielsen GP & 1997 & 3 \\
\hline 10 & $20-32 *$ & AS & 1 & Nielsen GP & 1997 & 3 \\
\hline 11 & $20-32 *$ & AS & III & Nielsen GP & 1997 & 3 \\
\hline 12 & 27 & AS & 1 & Nucci MR & 1998 & 17 \\
\hline 13 & 28 & AS & I & Jha S & 2005 & 20 \\
\hline 14 & 31 & AS & I & Quesenberry CD & 2005 & 21 \\
\hline 15 & 33 & AS & IV & Nara M & 1996 & 15 \\
\hline 16 & 35 & AS & IV & Nucci MR & 1998 & 17 \\
\hline 17 & 38 & AS & IV & Twu NF & 1999 & 11 \\
\hline 18 & 40 & AS & IV & Platt JS & 1999 & 14 \\
\hline 19 & 42 & AS & IV & Patel T & 1991 & 13 \\
\hline 20 & 42 & AS & 1 & Nucci MR & 1998 & 17 \\
\hline 21 & 46 & AS & 1 & Furihata M & 1998 & 19 \\
\hline 22 & 67 & AS & III & Bradford L & 2009 & 18 \\
\hline 23 & 81 & AS & 1 & Bösmüller H & 2011 & \\
\hline 24 & $20-32 *$ & Mature cystic teratoma + AS & III & Nielsen GP & 1997 & 3 \\
\hline 25 & $20-32 *$ & Mature cystic teratoma + AS & III & Nielsen GP & 1997 & 3 \\
\hline 26 & 30 & Mature cystic teratoma + AS & III & den Bakker MA & 2006 & 2 \\
\hline 27 & 32 & Mature cystic teratoma + AS & IV & Contreras AL & 2009 & 1 \\
\hline 28 & 37 & Mucinous cystadenocarcinoma + AS & I & Jylling AM & 1999 & 5 \\
\hline 29 & 45 & Borderline serous cystadenocarcinoma + AS & IV & Pillay K & 2001 & 6 \\
\hline 30 & 77 & Mucinous cystadenoma + AS & III & Ongkasuwan C & 1982 & 4 \\
\hline 31 & 65 & Ovarian fibroma + AS & I & Cambruzzi E & 2010 & 7 \\
\hline
\end{tabular}

* age not specified.

the periphery a thick fibrose zone was visible with some edema and foci of well formed angiomatous proliferations, lined by atypical endothelial cells (Figure 2, 3, 4). It was interesting to note that the spindle shaped highgrade malignant part of the lesion was restricted to the immediate portion of the tumor surrounding the cyst, whereas the angiomatous proliferation at the periphery was much better differentiated. Intact fibrous ovarian stroma could only be identified in areas bordering the intact peritoneal capsule.

The central highly atypical fusiform tumor infiltrate showed intense staining for CD31, reacted weakly for WT1, but had lost expression of CD34. There were nearly no remaining vascular spaces, and we found a Mib-score of $60 \%$. The more angiomatoid proliferation in the periphery did express both, CD31 and CD34, and Ki-67 was expressed only in some of the atypical endothelial cells (Mib-score $<10 \%)$. HHV8, epithelial markers (CK7, CAM 5.2, EMA), and smooth muscle actin were negative. Fluorescent in situ hybridisation for SYT-SSX $(X ; 18)$ was performed with LSI SYT Dual Colour Break Apart probe (18q11.2, Abbott, North Chicago, Illinois, USA) and was negative. Based on these findings, the patient was diagnosed with primary angiosarcoma of the ovary, high grade.

\section{Discussion}

Ovarian angiosarcoma (AS) is with rare exceptions a disease of premenopausal woman. Only two patients have been reported in postmenopausal age $[7,18]$ and the 81 years old woman described in this report is the oldest patient with this disease in the literature. AS of the ovary is very rare with only two small case series published so far, one with 4 and the other with 7 cases $[3,17]$. In both publications ovarian AS were described as morphological heterogenous tumors, a fact 


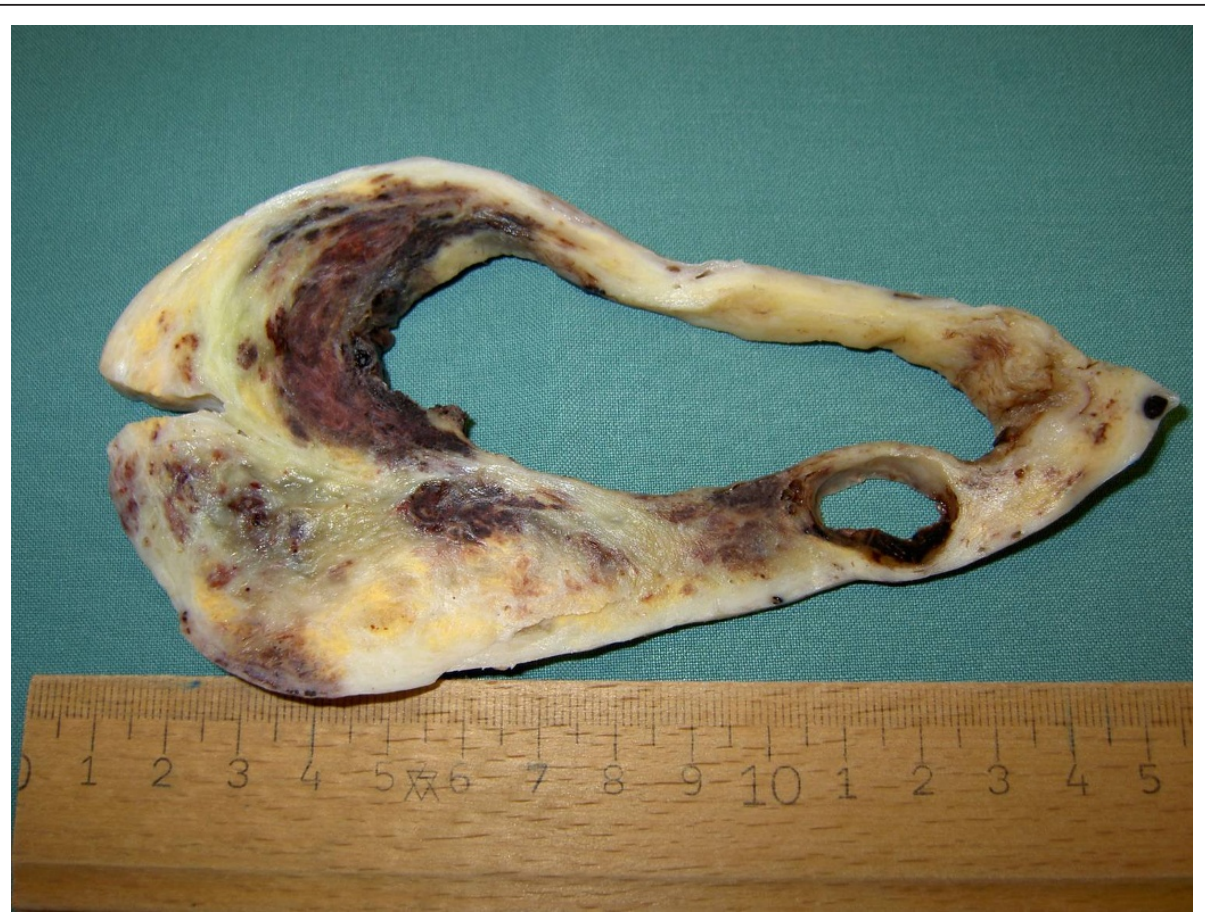

Figure 1 Cut surface of the right ovary featuring a centrally located tumor associated cyst.

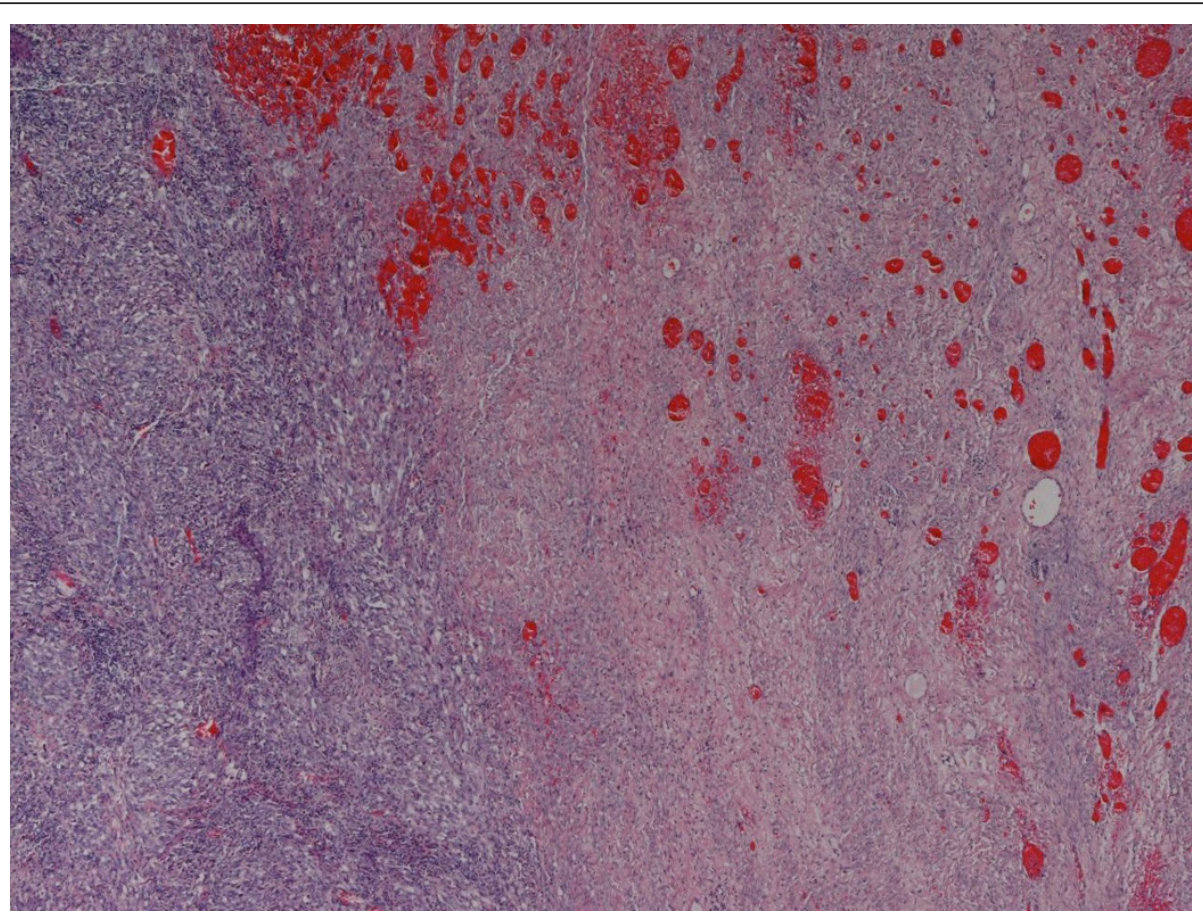

Figure 2 Transformation from centrally located angiosarcoma high grade (left) to more vasculated and well differentiated tumor areas in the periphery; H\&E $40 \times$. 


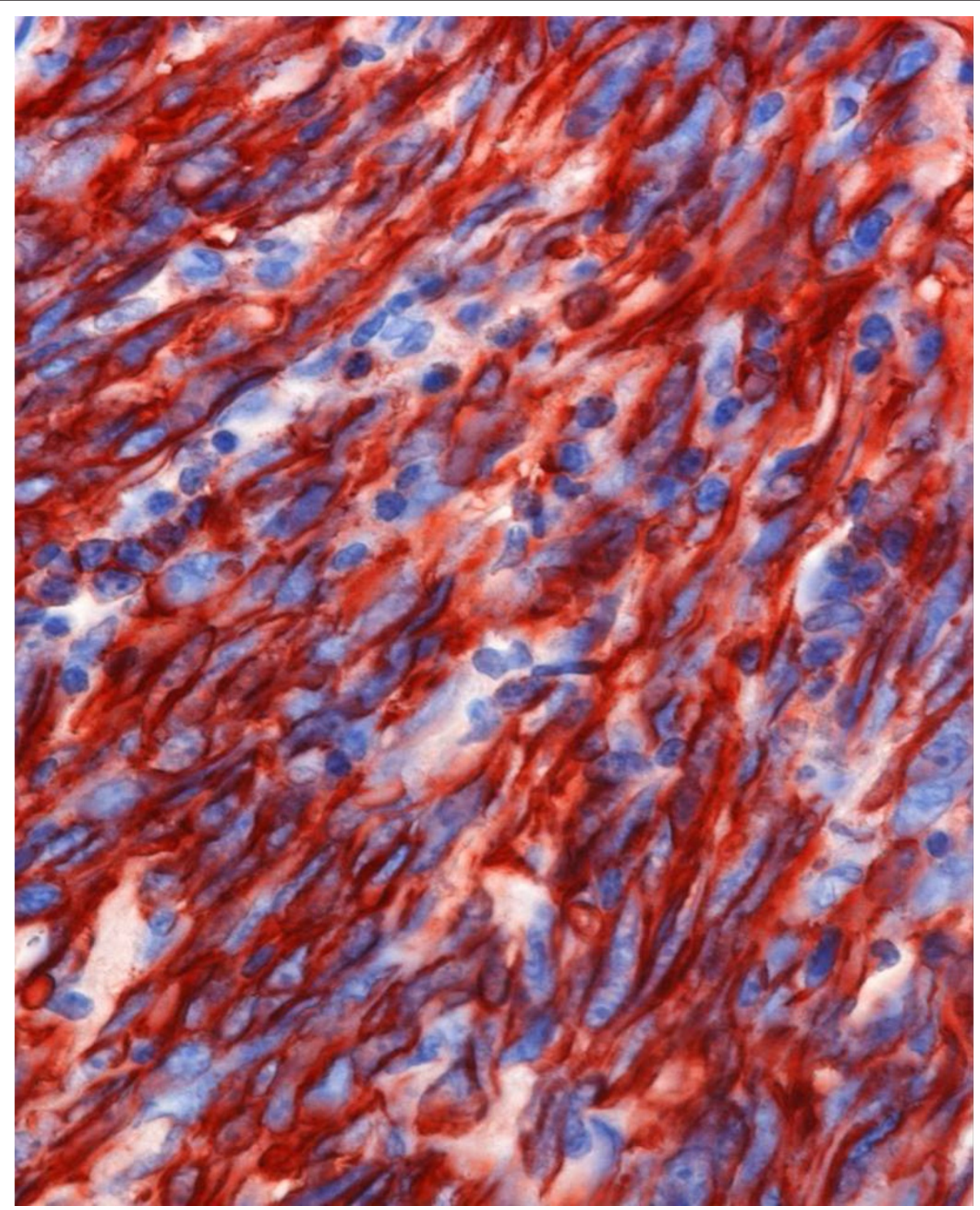

Figure 3 Centrally located angiosarcoma high grade with fusiform tumor component. CD31 staining 400x.

emphasized in a few other case reports too. The tumor described in this report represented high grade AS only in its central part, towards the periphery an atypical angiomatous proliferation was obvious, alternating with areas of intense fibrosis. A Mib-score of $60 \%$ and the marked pleomorphism with atypical mitotic figures in the central areas are striking features for malignancy, so there was no evidence for reactive angioma (Figure 5). Massive fibrosis may obscure a malignant tumor, leading to the misdiagnosis of fibroma or thecoma, similar to our case in the frozen section diagnosis, but nevertheless AS may coexist with true ovarian fibroma [7]. However, massive hemorrhage usually is present and suggests malignancy. Fusiform and fibrous aspects together with only sparse formation of capillary-like spaces, like in our tumor, may focally mimic myogenous origin or metastasis, respectively, but negativity of actin and expression of vascular markers supported the diagnosis of angiosarcoma. Synovial sarcoma was excluded by negative immunohistochemical staining for epithelial markers and inconspicuous SYT-SSX fluorescent in situ hybridisation [25].

Of 31 reported cases of ovarian angiosarcomas, 23 were pure lesions without coexisting benign or malignant epithelial components. In 5 reports, angiosarcoma was found to be associated with mature cystic teratoma, and in this context it was discussed, whether angiosarcoma is a sarcomatous teratoma, particularly those tumors occurring in younger women[1-3]. In another 3 cases mucinous cystadenoma, mucinous cystadenocarcinoma and borderline serous tumor were coexisting to 


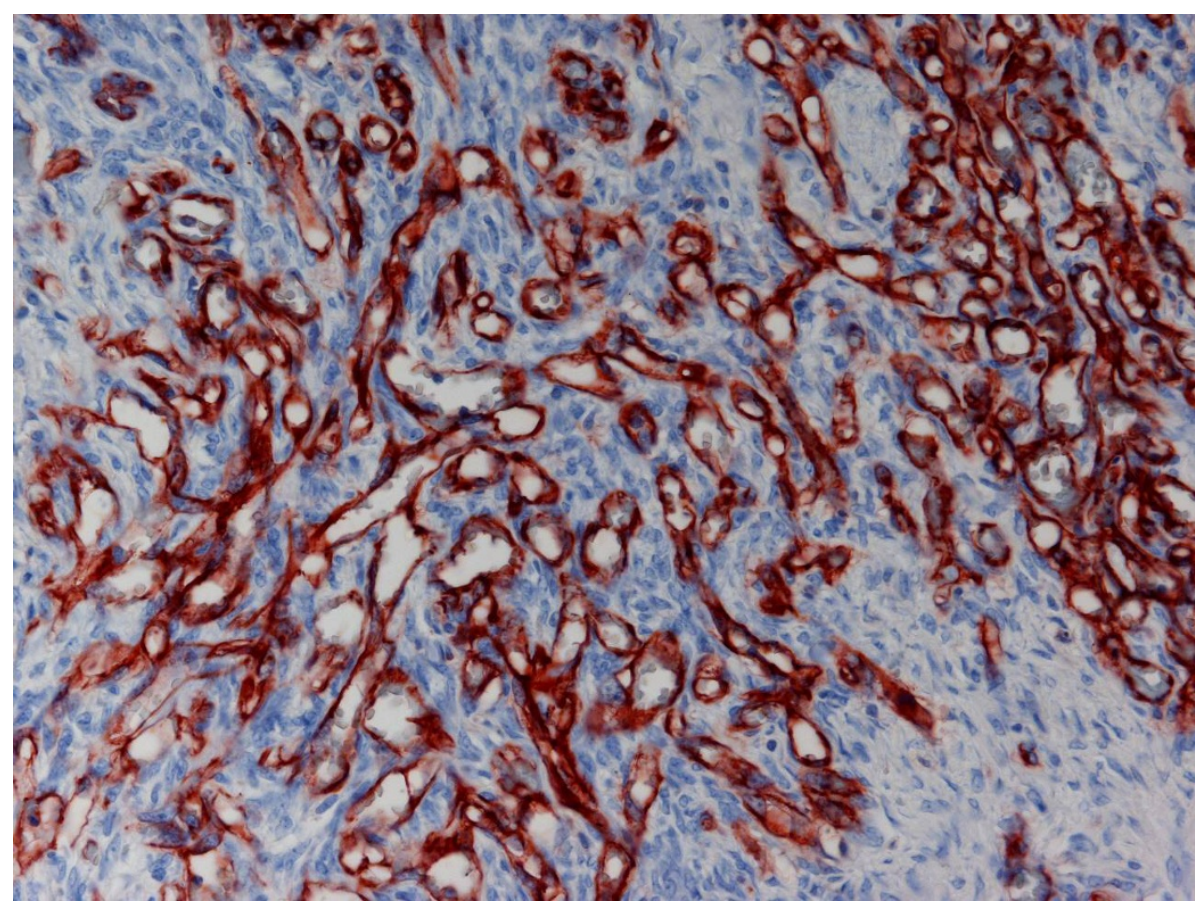

Figure 4 Atypical vascular proliferation in the cortical areas of the ovary. CD31 staining 100x.

ovarian AS, rendering the diagnosis adenosarcoma and carcinosarcoma, respectively [4-6], and putting ovarian AS into the context of malignant mesodermal mixed tumor (MMMT) [22]. Angiosarcoma itself may show epitheloid features and can therefore be mistaken for carcinoma or metastasis, and one published case had a predominant reticular growth pattern resembling yolk sac tumor [17].

\section{Conclusions}

These examples show that the suspicion of ovarian AS opens a broad range of differential diagnostic

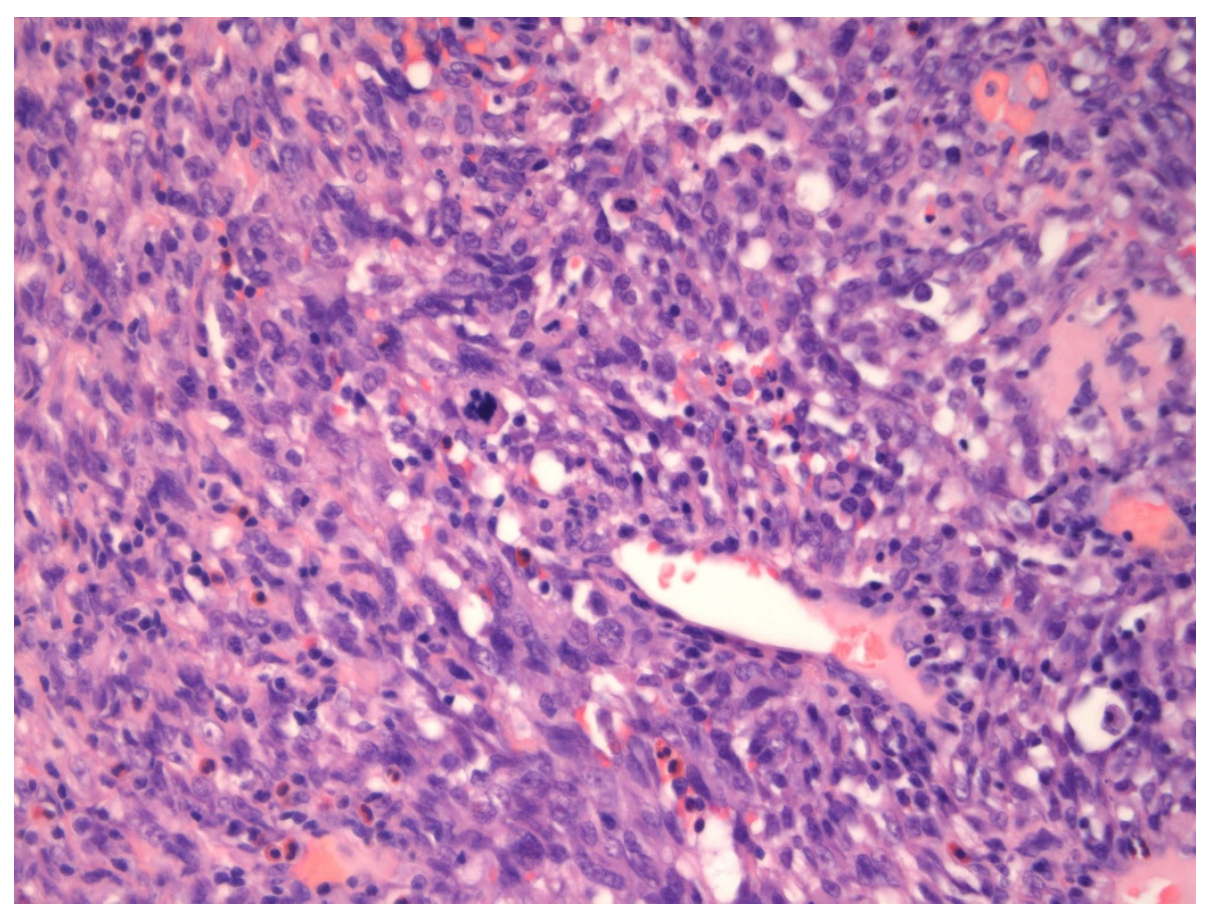

Figure 5 Centrally located high grade angiosarcoma exhibiting atypical mitosis; H\&E 200X 
considerations. The correct histopathological diagnosis, however, is of importance because prognosis of ovarian AS is uniformly poor. This could be related to the fact that most patients are diagnosed with advanced disease in stage III or IV. Although patients with stage I disease were shown to survive and even become pregnant $[3,20]$, there are also reports on fatalities of patients with early stage disease.

\section{Consent}

Written informed consent was obtained from the patient for publication of this case report and any accompanying images. A copy of the written consent is available for review by the Editor-in-Chief of this journal.

\section{Author details}

'Department of Pathology, Krankenhaus Barmherzige Schwestern Linz, Austria. ${ }^{2}$ Department of Gynecology, Krankenhaus der Elisabethinen Linz, Austria. ${ }^{3}$ laboratory of Molecular Biology und Tumorcytogenetics, I. Internal Department, Krankenhaus Barmherzige Schwestern Linz, Austria.

${ }^{4}$ Department of Pathology, University Hospital of Halle-Wittenberg, Germany.

\section{Authors' contributions}

HB conceived the case report and drafted the manuscript, CG and SP carried out histology and immunohistochemistry, DW supplied clinical data, GW carried out molecular analyses, $\mathrm{SH}$ supervised the case report and participated in its design and coordination. All authors have read and approved the final manuscript.

\section{Declaration of Competing interests}

The authors declare that they have no competing interests.

Received: 21 April 2011 Accepted: 14 July 2011 Published: 14 July 2011

\section{References}

1. Contreras AL, Malpica A: Angiosarcoma arising in mature cystic teratoma of the ovary: A case report and review of the literature. Int $J$ Gynecol Pathol 2009, 28:453-457.

2. den Bakker MA, Ansink AC, Ewing-Graham PC: "Cutaneous-type" angiosarcoma arising in a mature cystic teratoma of the ovary. $J$ Clin Pathol 2006, 59:658-660.

3. Nielsen GP, Young RH, Prat J, Scully RE: Primary angiosarcoma of the ovary: a report of seven cases and review of the literature. Int I Gynecol Pathol 1997, 16:378-382.

4. Ongkasuwan C, Taylor JE, Tang CK, Prempree T: Angiosarcomas of the uterus and ovary: clinicopathologic report. Cancer 1982, 49:1469-1475.

5. Jylling AM, Jørgensen L, Hølund B: Mucinous cystadenocarcinoma in combination with hemangiosarcoma in the ovary. Pathol Oncol Res 1999, 5:318-319.

6. Pillay K, Essa AS, Chetty R: Borderline serous cystadenocarcinoma with coexistent angiosarcoma: an unusual form of ovarian carcinosarcoma. Int J Surg Pathol 2001, 9:317-321.

7. Cambruzzi E, Pegas KL, Milani DM, Cruz RP, Guerra EH, Ferrari MB: Angiosarcoma arising in an ovarian fibroma: a case report. Pathol Res Int 2010, 842592

8. Souza FF, Katkar A, den Abbeele AD, Dipiro PJ: Breast angiosarcoma metastatic to the ovary. Case Report Med 2009, 381015.

9. Cantú De León D, Pérez Montiel D, Chanona Vilchis J: Unusual case of subcutaneous angiosarcoma metastatic to the ovary. Pathol Oncol Res 2007, 13:379-381.

10. Cunningham MJ, Brooks JS, Noumoff JS: Treatment of primary ovarian angiosarcoma with ifosfamide and doxorubicin. Gynecol Oncol 1994, 53:265-268.
11. Twu NF, Juang CM, Yeng MS, Lu CJ, Lai CZ, Chao KC: Treatment of primary pure angiosarcoma of ovary with multiple lung metastases: a case report. Eur J Gynecol Oncol 1999, 20:383-385.

12. Bouchi J, el Asmar B, Couetil JP, Acker M, Taleb N, Gedeon E, Bedran F: Angiosarcoma of the ovary with lung metastases. Ann Chir 1993, 47:740-741.

13. Patel T, Ohri SK, Sundaresan M, Jackson J, Desa LA, Davey AT, Spencer J: Metastatic angiosarcoma of the ovary. Eur J Surg Oncol 1991, 17:295-299.

14. Platt JS, Rogers SJ, Flynn EA, Taylor RR: Primary angiosarcoma of the ovary: a case report and review of the literature. Gynecol Oncol 1999, 73:443-446.

15. Nara M, Sasaki T, Shimura S, Yamamoto M, Oshiro T, Kaiwa Y, Kurokawa Y, Tezuka F, Shirato K: Diffuse alveolar hemorrhage caused by lung metastasis of ovarian angiosarcoma. Intern Med 1996, 35:653-656.

16. Davidson B, Abeler VM: Primary ovarian angiosarcoma presenting as malignant cells in ascites: case report and review of the literature. Diagn Cytopathol 2005, 32:307-309.

17. Nucci MR, Krausz T, Lifschitz-Mercer B, Chan JK, Fletcher CD: Angiosarcoma of the ovary: clinicopathologic and immunohistochemical analysis of four cases with a broad morphologic spectrum. Am J Surg Pathol 1998, 22:620-630.

18. Bradford L, Swartz K, Rose S: Primary angiosarcoma of the ovary complicated by hemoperitoneum: a case report and review of the literature. Arch Gynecol Obstet 2010, 281:145-150.

19. Furihata M, Takeuchi T, Iwata J, Sonobe H, Ohtsuki Y, Wakatsuki A Morioka N, Sagara Y: Primary ovarian angiosarcoma: a case report and literature review. Pathol Int 1998, 48:967-973.

20. Jha S, Chan KK, Poole CJ, Rollason TP: Pregnancy following recurrent angiosarcoma of the ovary-a case report and review of literature. Gynecol Oncol 2005, 97:935-937.

21. Quesenberry CD, Li C, Chen AH, Zweizig SL, Ball HG: Primary angiosarcoma of the ovary: a case report of Stage I disease. Gynecol Oncol 2005, 99:218-221.

22. Lifschitz-Mercer B, Leider-Trejo L, Messer G, Peyser MR, Czernobilsky B: Primary angiosarcoma of the ovary: a clinicopathologic, immunohistochemical and electronmicroscopic study. Pathol Res Pract 1998, 194:183-187.

23. Serrano C, García Á, Brana I, Pérez-Benavente A, Oaknin A: Angiosarcoma of the ovary: is it always a lethal disease? J Clin Oncol 2010, 28:e675-677.

24. Evtushenko NT: Angiosarcoma of the ovary in a 7-year old girl. Akush Ginekol (Mosk) 1958, 34:105.

25. Smith CJ, Ferrier AJ, Russell P, Danieletto S: Primary synovial sarcoma of the ovary: first reported case. Pathology 2005, 37:385-387.

doi:10.1186/1746-1596-6-65

Cite this article as: Bösmüller et al:: Primary angiosarcoma of the ovary with prominent fibrosis of the ovarian stroma. Case report of an 81year old patient. Diagnostic Pathology 2011 6:65.

\section{Submit your next manuscript to BioMed Central and take full advantage of:}

- Convenient online submission

- Thorough peer review

- No space constraints or color figure charges

- Immediate publication on acceptance

- Inclusion in PubMed, CAS, Scopus and Google Scholar

- Research which is freely available for redistribution 